\title{
QUANTITATIVE MECHANISTIC STUDIES IN SIMULTANEOUS FLUID FLOW AND INTESTINAL ABSORPTION USING STEROIDS AS MODEL SOLUTES
}

\author{
I. KOMIYA *, J.Y. PARK, A. KAMANI, N.F.H. HO ** and W.I. HIGUCHI
}

College of Pharmacy. The University of Michigan, Ann Arbor, Mich. 48109 (U.S.A.)

(Received September 11th, 1979)

(Accepted November 6th, 1979)

\section{SUMMARY}

The interplay of flow-rate, aquec's boundary layer and membrane permeability coefficients, solute lipophilicity and intes'inal length has been quantitatively determined for the in situ situation of bulk fluid flow and concurrent steady-state absorption of steroids in the small intestines of the rat. Seven steroids ranging in 3 orders of magnitude in n-octanol/water partition coefficients were used.

The results followed the physical model predictions described by:

$$
\frac{C(\ell)}{C(0)}=\exp \left(-\frac{2 \pi \mathrm{rl}}{\mathrm{Q}} \cdot \frac{\mathrm{P}_{\mathrm{aq}}}{1+\mathrm{P}_{\mathrm{aq}} / \mathrm{P}_{\mathrm{m}}}\right)
$$

where $C(\ell) / C(0)$ is the fraction of steroid remaining in the intestinal lumen of length $\ell, r$ is the effective lumenal radius, $\mathbf{Q}$ is the flow-rate, $\mathbf{P}_{\mathrm{i}: \mathrm{q}}$ and $\mathbf{P}_{\mathbf{m}}$ are the respective aqueous boundary layer and membrane permeability coefficients. The log fraction of steroids remaining in the lumen was linear with intestinal length at various flow rates. The fraction absorbed increased with slower flow-rates at any given length due to the longer residence time. The fraction of steroid absorbed vs log partition coefficient profiles as a function of flow-rate were significantly sigmoidal. The absorption rates of progesterone were aqueous boundary layer-controlled and the less lipophilic hydrocortisone were membrane-controlled. It is significant that the permeability of the aqueous boundary layer is proportional to $\mathrm{Q}^{\mathbf{0 . 4 4}}$.

\section{INTRODUCTION}

The purpose of this paper is to establish the interplay of flow-rate, aqueous boundary layer and membrane permeability, solute lipophilicity and intestinal length within an in

\footnotetext{
* Present address: Meiji Seika, Kaisha Ltd., Yokohama, Japan.

** To whom correspondence should be addressed.
} 
situ situation of simultaneous bulk fluid flow and absorption in the intestinal tract. A simple physical model is used to provide the framework for the experimental conditions and quantification of phenomenological transport parameters whereupon the rat and selective steroids are chosen to demonstrate the principles.

\section{THEORY}

As fluid containing drug from an infinite reservoir flows across the absorptive surface of an intestinal element taken as a right cylinder, there will be a concentration drop along the length of the element as schematically depicted in Fig. 1.

The fraction of drug remaining within a defined intestinal length at steady-state and the corresponding fraction of drug absorbed are described as follows (Ho and Higuchi, 1974; Ho et al., 1979):

$\frac{C(\ell)}{C(0)}=\exp \left(-\frac{2 \pi \mathrm{r} \ell}{Q}: \mathbf{P}_{z p p}\right)$

and

F.A. $=1-\frac{C(\ell)}{C(0)}$

where $\mathbf{C}(0)$ is the drug concentration from the infinite reservoir entering the intestinal lumen; $C(\ell)$, is the drug concentration leaving the intestinal lumen at intestinal length, $\ell$; F.A. is the fraction of drug absorbed; $r$ is the effective radius of the intestinal lumen in $\mathrm{cm} ; \ell$ is the intestinal length in $\mathrm{cm}$; $Q$ is the steady-state bulk fluid flow rate in $\mathrm{cm}^{3} / \mathrm{sec}$; and $P_{\text {app }}$ is the apparent permeability coefficient in $\mathrm{cm} / \mathrm{sec}$.

The apparent permeability coefficient is further defined by

$\frac{1}{\mathrm{P}_{\mathrm{app}}}=\frac{1}{\mathrm{P}_{\mathrm{aq}}}+\frac{1}{\mathrm{P}_{\mathrm{m}}}$

where $P_{\mathrm{aq}}$ is the permeability coefficient of the aqueous boundary layer adjacent to the mucosal membrane in $\mathrm{cm} / \mathrm{sec}$; and $P_{m}$ is the membrane permeability coefficient in $\mathrm{cm} /$

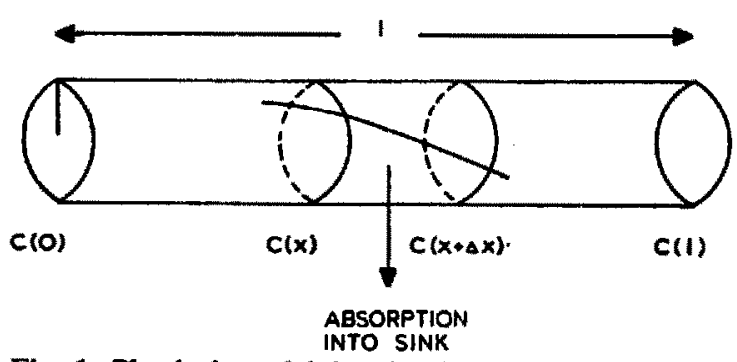

Fig. 1. Physical model for the simultaneous bulk fluid flow and absorption in the intestinal tract at steady-state. 
sec. As can be seen, the total mass transfer resistance is the sum of the resistances in series, i.e., the aqueous boundary layer and the membrane. When the partition coefficients of the permeating molecules are relatively high, the membrane resistance becomes negligible as compared to the aqueous boundary layer resistance. This is the aqueous boundary layer-controlled situation. The membrane resistance for rather hydrophilic solutes tends to be higher than that of the aqueous boundary layer.

When the diffusional rate across the aqueous boundary layer is the rate-determining factor, i.e., $P_{a q}<<P_{m}$, absorption is maximum; thus

F.A.max $=1-\exp \left(-\frac{2 \pi r \ell}{Q} \cdot P_{a q}\right)$

When the absorption process is membrane-controlled, i.e., $P_{a q} \gg P_{m}$, then

F.A. $=1-\exp \left(-\frac{2 \pi r l}{Q} \cdot P_{m}\right)$

It is seen that, on the one hand, $C(\ell) / C(0)$ and F.A. are explicitly affected by the flowrate, $Q$, since the flow-rate has a direct bearing on the residence time. The residence time, which is the time it takes a flowing liquid to displace a volume of liquid in the intestinal lumen, is readily estimated by dividing the lumenal volume of the intestinal segment by the flow-rate. On the other hand, the flow-rate will also influence the effective thickness of the aqueous boundary layer (Schlichting, 1955; Levich, 1962). Thus, the permeability and thickness of the aqueous boundary layer is related to the flow-rate by

$P_{\mathrm{aq}}=\frac{D_{\mathrm{aq}}}{\delta}=\mathrm{k} \mathrm{Q}^{\mathrm{n}}$

where $D_{\mathrm{aq}}$ is the aqueous diffusion coefficient in $\mathrm{cm}^{2} / \mathrm{sec} ; \delta$ is the effective thickness of the aqueous boundary layer in $\mathrm{cm} ; \mathrm{k}$ is a constant descriptive o the aqueous diffusivity of the solute, kinematic viscosity and geometrical factors; and $a$ is an exponent of which $0<\mathrm{n}<1$.

\section{MATERIALS AND METHODS}

The through-and-through perfusion method in studying in situ rat intestinal absorption was employed (Fig. 2). Sprague-Dawley albino rats, 275-315 g, were anesthetized with $2 \mathrm{ml}$ urethane $20 \%$ solution by intraperitoneal injection in equally divided doses given 15 min apart. After a midline abdominal incision was made, the small intestines were taken out with careful handling to avoid disturbance of the circulatory system. The proximal part of the jejunum was cannulated, connected to the syringe pump and perfused with normal saline solution. The small intestines became distended. The intestinal length desired for the absorption study was measured with a thread and then the distal end was cannulated and connected to the outflow glass tube of the perfusion assembly ${ }^{1}$. The

${ }^{1}$ Infusion pump, Harvard Apparatus Co., Dover, Mass. 


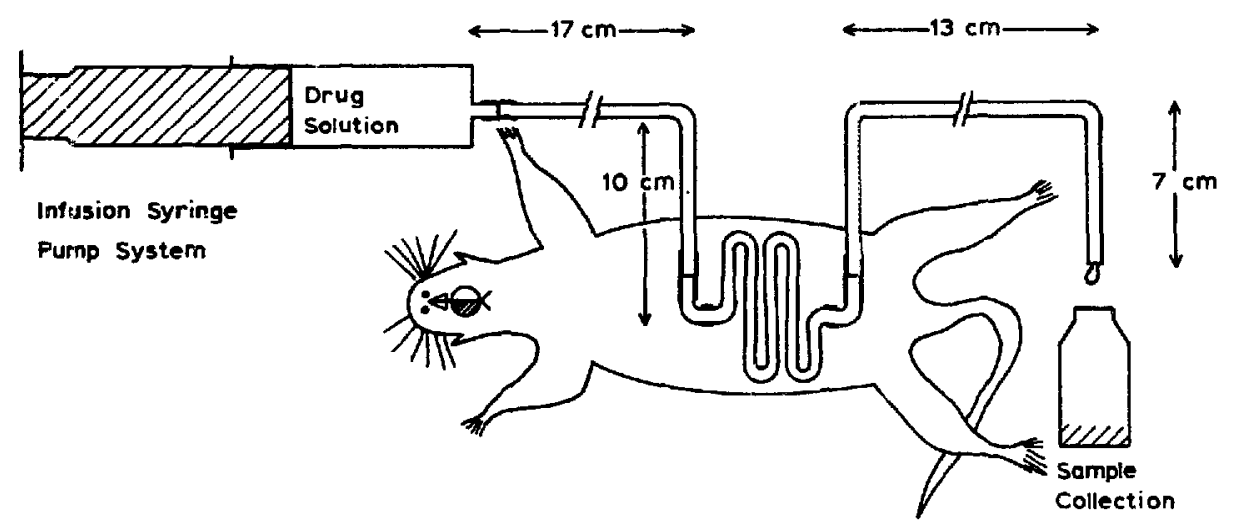

Fig. 2. Schematics of the through-and-through in situ rat iniestinal perfusion assembly.

dimensions of the cannula and glass tubing were $2 \mathrm{~mm}$ i.d. and $4 \mathrm{~mm}$ o.d. The washing of the intestinal lumen continued until the perfusate was visually clear.

Tritiated progesterone, testosterone, deoxycorticosterone, androst-4-ene-3,17-dione, corticosterone, dexamethasone and hydrocortisone were purchase $d^{2}$ and found to be chromatographically pure. Each steroid was dissolved in phosphate buffer, $\mathrm{pH} 6.0$, using potassum sulfate to adjust the osmolarity ${ }^{3}$ to $310 \mathrm{mOsm} / \mathrm{kg}$. The solution was infused into the intestines of various lengths and at different flow-rates. Although the flow-rate was regulated principally by the infusion pump settings, the rates were also determined for each experiment by measuring the outflow volume of liquid collected within time intervals. Outflow samples of radiolabeled steroids were collected at regular intervals in time from which $100 \mu \mathrm{l}$ was transferred with an automatic pipette into $10 \mathrm{ml}$ of scintillation cocktail and then assayed by the liquid scintillation counter.

Because of the geometry of the perfusion system seen in Fig. 2, there was intralumenal pressure leading to distention of the intestines. Under these conditions the effective lumenal radius was about $0.18 \mathrm{~cm}$. Also, all intestinal segments used were carefully laid out in a uniform $\mathrm{S}$ - to multi-S arrangement depending upon the length to avoid kinks and ensure some degree of uniformity in hydrodynamics. There was 1 bend for the $10 \mathrm{~cm}$ intestinal length, 3 bends for the $20 \mathrm{~cm}$ length and 5 bends for the $33.3 \mathrm{~cm}$ length. Care was taken rot to disturb the blood supply to the intestines. Since curvature of tubes is known to affect the flow dynamics of fluids by producing turbulence, efforts were made to investigate the effect of straight intestinal arrangements on the absorption rates. This could not be accomplished without dissecting the mesentery and blood vessels; therefore, this was abandoned. Although measurements of intestinal length were made in the beginning during the cannulation procedure, measurements were also made during the course of the absorption experiments. In most of the studies, different lengths of the small intestines used started from the ligament of Treitz; while in other situations, the various lengths began $2 \mathrm{~cm}$ from the ileocecal junction. The intestinal length did not change during the experimental period.

\footnotetext{
2 New England Nuclear, Boston, Mass.

"Osmette, Model A, Precision Systems, Sudbury, Mass.
} 
TABLE 1

INTRALUMENAL PRESSURE AND OUTER CIRCUMFERENCE MEASUREMENTS AT VARIOUS PERFUSION FLOW RATES

\begin{tabular}{|c|c|c|c|c|}
\hline \multirow{3}{*}{$\begin{array}{l}\text { Flow-rate } \\
(\mathrm{ml} / \mathrm{min})\end{array}$} & \multicolumn{2}{|c|}{ Pressure ${ }^{a}$ at $37^{\circ} \mathrm{C}\left(\mathrm{mm} \mathrm{H}_{2} \mathrm{O}\right)$} & \multirow{2}{*}{\multicolumn{2}{|c|}{$\begin{array}{l}\text { Outer circumference of } 33.3 \mathrm{~cm} \\
\text { jejunum }(\mathrm{cm})\end{array}$}} \\
\hline & \multirow[t]{2}{*}{$\mathbf{n}$} & \multirow[t]{2}{*}{ Average \pm S.D. } & & \\
\hline & & & $\mathbf{n}$ & Average \pm S.D. \\
\hline 0.247 & 5 & $34 \pm 0.2$ & 4 & $2.0 \pm 0.1$ \\
\hline 1.28 & 5 & $35 \pm 0.1$ & 4 & $2.0 \pm 0.1$ \\
\hline 4.213 & 5 & $39 \pm 0.2$ & 4 & $2.1 \pm 0.1$ \\
\hline
\end{tabular}

The term $\mathrm{n}$ is the number of measurements in two rats. The pressure in $\mathrm{mm} \mathrm{Hg}$ is $\mathrm{P}_{\mathrm{mmH}_{2}} \mathrm{O} / 13.5$.

The estimation of the effective radius of the distended intestinal lumen was pursued in two ways. With the use of non-absorbable $\left[{ }^{14} \mathrm{C}\right]$ polyethylene glycol 4000 , it was found that $2.2 \mathrm{ml}$ filled a $22 \mathrm{~cm}$ jejunal segment. Assuming the intestines to be a right cylindrical tube, the radius was $0.178 \mathrm{~cm}$. In the second approach the outer circumference of the distended intestines was measured with a thread and the thickness of the intestines was determined with an electronic tissue thickness gauge ${ }^{4}$. The following expression was used to calculate the radius:

$r_{\text {lumen }}=\frac{C_{\text {outside }}-2 \pi \Delta r}{2 \pi}$

where $r_{\text {lumen }}$ is the lumenal radius; $C_{\text {outside }}$ is the outer circumference of the intestines; and $\Delta r$ is the thickness of the intestines.

With $\mathrm{C}_{\text {outside }}=2.1 \mathrm{~cm}$ and $\Delta \mathrm{r}=0.15 \mathrm{~cm}$, the lumenal radius is found to be $0.184 \mathrm{~cm}$. Both approaches are in good agreement.

Intralumenal pressure and intestinal distention measurements, independent of absorption studies with radiolabeled steroids, were made at various flow-rates of buffered $\mathrm{pH}$ 6.0 perfusion solution. The water manometer ${ }^{5}$ was connected to the inflow cannula at the proximal end of the small intestines. The results in Table 1 show that there was a smail change in the pressure (about 10\%) over a 17-fold change in flow-rates from 0.247 to $4.2 \mathrm{ml} / \mathrm{min}$ with no apparent change in the distention of the intestinal lumen. These results are almost identical to those found by Lewis and Fordtran (1975) and, at these pressures, mucosal blood flow is not affected (Boley and Veith, 1971). Also, mucosal surface area is unchanged within the range of flow rates used.

Water fluxes were assessed during the steady-state absorption period with the aid $0 \hat{i}$ $\left[{ }^{14} \mathrm{C}\right]$ polyethylene glycol 4000 . No net gain or loss of water was detected.

\footnotetext{
${ }^{4}$ Skin graft thickness gauge, Michigan Research Corp., Ann Arbor, Mich.

5 Manometer, Cat. No. 4330, Pharmaseal Labs., Glendale, Calif. The passageway of the 2-way stopcock was enlarged by drilling so that the diameter was nearly the same as the inflow cannula.
} 


\section{RESULTS AND DISCUSSION}

\section{General description of absorption studies}

Fig. 3 represents a typical plot of the change in the outflow-to-inflow concentration ratio with time as a function of bulk flow-rate. The non-steady-state sigmoidal region is indicative of longitudinal spreading within the perfused system. The plateau region is the steady-state fraction of steroid remaining in the intestinal segment. Table 2 gives the summary of the steady-state fraction of steroids absorbed at different flow-rates and intestinal lengths beginning from the jejunum or the ileum. As can be seen, the reproducibility is good.

In Fig. 4 the logarithm of the fractions of progesterone and hydrocortisone remaining in the small intestines are found to be essentially linear with intestinal length at all flowrates employed. It is significant that the experimental results are in excellent agreement with the theoretical predictions made on the basis of taking only one data point of $C(\ell) /$ $C(0)$, for example, at the intestinal length of $33.3 \mathrm{~cm}$ and flow-rate of $0.494 \mathrm{ml} / \mathrm{min}$ for progesterone and hydrocortisone. At any given length and flow-rate, progesterone is more rapidly absorbed than the less lipophilic hydrocortisone. In general, the fraction absorbed is expectedly higher with decreasing flow-rates because of the longer residence time for absorption to occur, although lower flow-rates tend to increase the effective thickness of the aqueous boundary layer and, thereby, decrease the permeability of the aqueous layer.

In considering all the steroids employed in this study, a plot of the fraction absorbed in the jejunum vs the logarithm of the partition coefficient in n-octanol/water as a function of flow-rate shows sigmoidal-like relationships (Fig. 5). The absorption of androst-4ene-3,17-dione, deoxycorticosterone, testosterone and progesterone plateaus within a range of $\log$ partition coefficient of $2.7-4.0$ Generally, the fraction of each steroid absorbed is larger at low flow-rates than that at high flow-rates due, effectively, to the differences in residence time. However, as expected by the theoretical model, the differences in the fraction absorbed due to flow-rate are much larger among the highly lipophilic

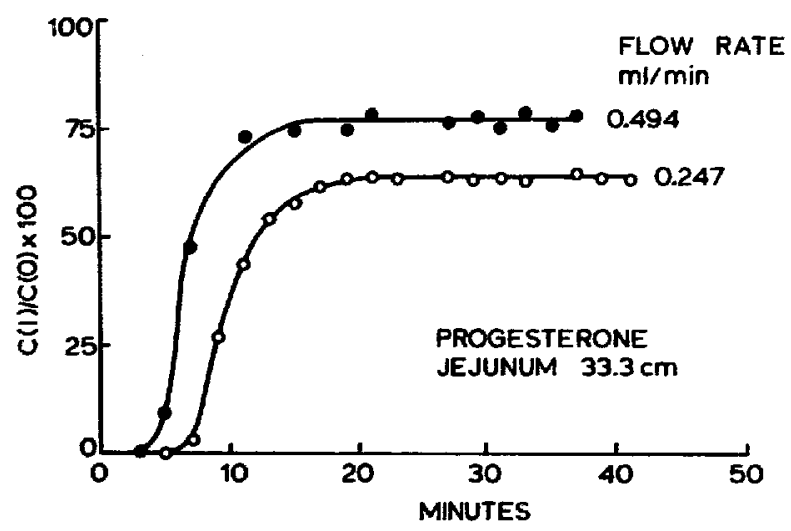

Fig. 3. Typical outflow-to-inflow concentration ratio profiles with time at various flow-rates illustrating the non-steady and steady-state situations. 


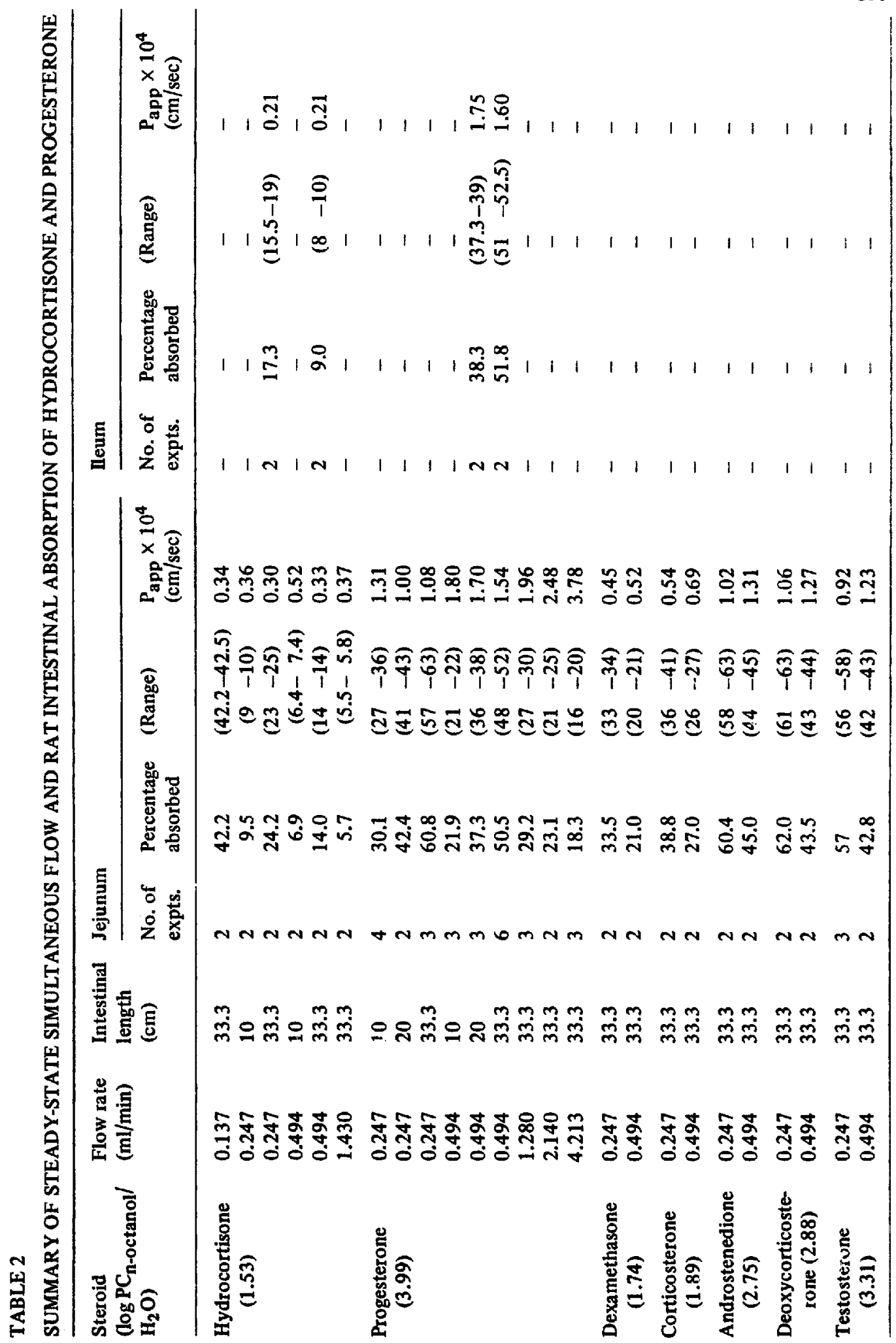




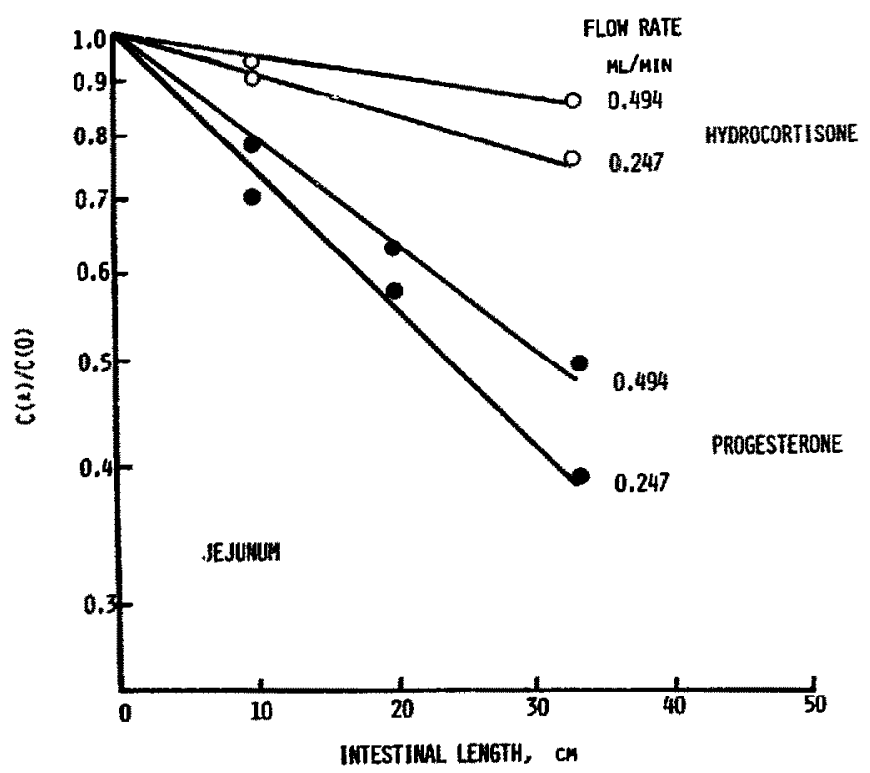

Fig. 4. Semilogarithmic plot of fraction of steroids remaining in various intestinal lengths as a function of fuid flow-rate.

steroids than among the less lipophilic steroids such as hydrocortisone, dexamethasone and corticosterone.

\section{Permeability coefficient determinations}

The apparent permeability coefficients of the steroids found in Table 2 were calculated from the theoretical model using the following expression:

$P_{\mathrm{app}}=-\frac{Q}{2 \pi \mathrm{r} \ell} \cdot \ln \frac{\mathrm{C}(\ell)}{\mathrm{C}(0)}$

Fig. 6 shows the sigmoidal-like correlation of the apparent permeability coefficients with the log partition coefficients of the steroids. In contrast to Fig. 5, the $P_{\text {app }}$ increases generally with flow-rate. Differences in $P_{\text {epp }}$ values as a function of flow-rates are maximum in the plateau region in Fig. 6 where the absorption rates of the rather lipophilic steroids are aqueous boundary layer-controlled. Identical shapes of the curves have been reported on the rat intestinal absorption of steroids by the in situ Doluisio method (Ho et al., 1979).

In plotting the apparent permeability coefficient against the flow-rate on a $\log -\log$ scale (Fig. 7), one observes a linear relationship for progesterone over a 17-fold range of flow-rates (about $0.25-4.2 \mathrm{ml} / \mathrm{min}$ ) indicating that the transport rate across the aqueous boundary layer is essentially the rate-determining factor in the absorption process. Estimates of the aqueous boundary layer thickness as a function of flow-rates in Table 3 range from $708 \mu \mathrm{m}$ for $0.247 \mathrm{ml} / \mathrm{min}$ to $212 \mu \mathrm{m}$ for $4.2 \mathrm{ml} / \mathrm{min}$. In sharp contrast to 


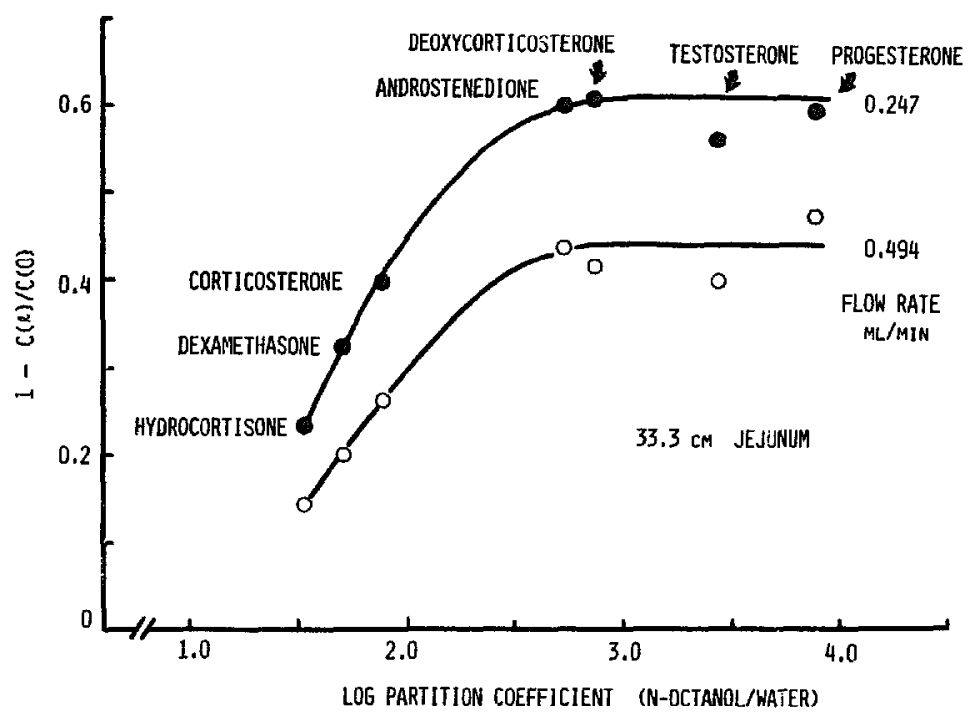

Fig. 5. Fraction of steroids absorbed in $33.3 \mathrm{~cm}$ jejunum segment vs lipophilicity in terms of n-octanol/water partition coefficients as a function of flow-rate.

progesterone, the transport of hydrocortisone is effectively membrane-controlled as evidenced by the lack of the effect of flow-rate on the apparent permeability coefficient.

The use of a double reciprocal plot of $P_{a p p}$ and $Q^{n}$ permits the calculation of the membrane permeability of progesterone. Such a plot conforms with the theoretical predictions of Eqns. 3 and 6 ; thus,

$\frac{1}{P_{\mathrm{app}}}=\frac{1}{\mathrm{P}_{\mathrm{m}}}+\frac{1}{\mathrm{kQ}^{\mathrm{n}}}$

It is apparent that the permeability coefficient, $P_{a p p}$, increases with flow-rate, $Q$, because

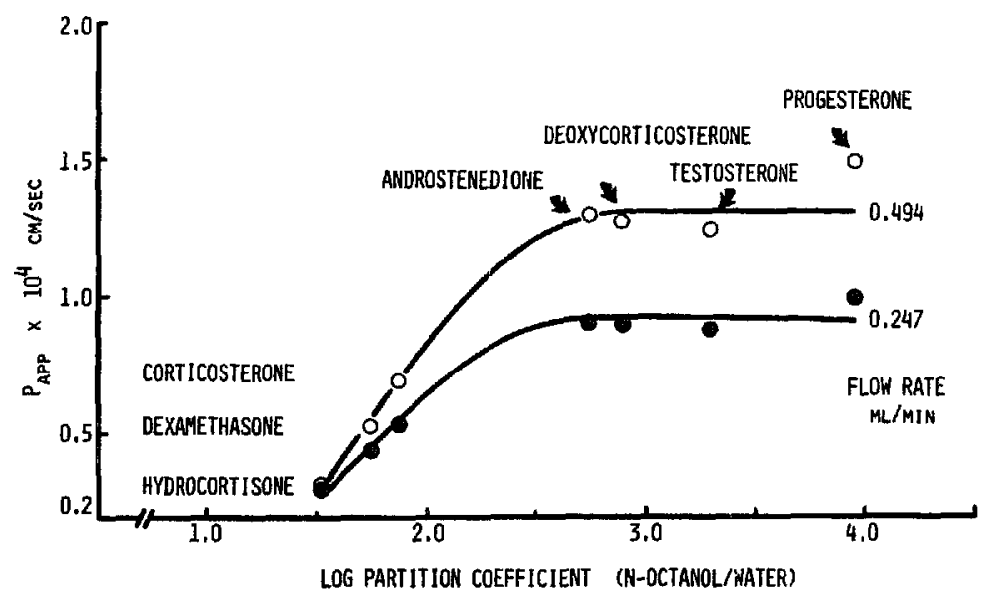

Fig. 6. Apparent permeability coefficients of steroids in the rat jejunum vs n-octanol/water partition coefficients as a function of flow-rate. 
TABLE 3

PERMEABILITY COEFFICIENTS AND EFFECTIVE THICKNESSES OF THE AQUEOUS BOUNDARY LAYER AS A FUNCTION OF FLOW-RATE AND ESTIMATES OF SLRFACE ROUGHNESS OF THE SMALL INTESTINES OF THE KAT

\begin{tabular}{llllll}
\hline $\begin{array}{l}\text { Flow-rate Q } \\
(\mathrm{m} / \mathrm{min})\end{array}$ & $\begin{array}{l}\text { Linear flow } \\
\text { velocity } \mathrm{c}_{\boldsymbol{\beta}} \\
(\mathrm{cm} / \mathrm{min})\end{array}$ & $\begin{array}{l}\text { Permeability of } \\
\text { boundary layer, } \\
\left(\mathrm{P}_{\mathrm{aq}} \times 10^{4} \mathrm{~cm} / \mathrm{sec}\right)\end{array}$ & $\begin{array}{l}\text { Effective boundary } \\
\text { layer thickness }{ }^{\mathrm{s}} \delta \\
(\mu \mathrm{m})\end{array}$ & $\begin{array}{l}\text { Estimate }^{\mathrm{b}} \\
\text { of } \delta / \mathrm{r}\end{array}$ & $\begin{array}{l}\text { Estimate }^{\mathrm{b}} \\
\text { of } \delta / \mathrm{h}\end{array}$ \\
\hline 0.247 & 2.42 & 1.13 & 708 & 0.39 & 1.18 \\
0.494 & 4.85 & 1.68 & 476 & 0.26 & 0.79 \\
1.28 & 12.57 & 1.96 & 408 & 0.23 & 0.68 \\
2.14 & 21.02 & 2.31 & 346 & 0.19 & 0.58 \\
4.213 & 41.39 & 3.78 & 212 & 0.12 & 0.35 \\
\hline
\end{tabular}

a Effective thickness of aqueous boundary layer: $6=\frac{D_{\mathrm{aq}}}{\mathrm{P}_{\mathrm{aq}}}=\frac{8 \times 10^{-6}}{\mathrm{P}_{\mathrm{aq}}}$.

b Radius of intestinal lumen, $r=1800 \mu \mathrm{m}$ and villus height, $h=600 \mu \mathrm{m}$ (Verzar and McDougall, 1967 ).

c The linear flow velocity, $\beta=Q / \pi \mathrm{r}^{2}$.

of the thinning of the aqueous boundary layer. In the limit of infinite flow-rates, $P_{a p p}$ equals $P_{m}$, the membrane permeability coefficient. An initial estimate of $n=0.4$ and $k=10^{-3.0}$ was obtained from the slope and intercept in Fig. 7, whereupon non-linear regression analysis of the progesterone data in Table 2 with respect to Eqn. 9 was performed. The results of best estimates are shown in Fig. 8 in which $n=0.44$ and $P_{m}=$ $2.5 \times 10^{-3} \mathrm{~cm} / \mathrm{s}$.

All of the foregoing results and discussions concentrated on the absorption in the je junum. However, a few experiments were performed in the ileum with progesterone and

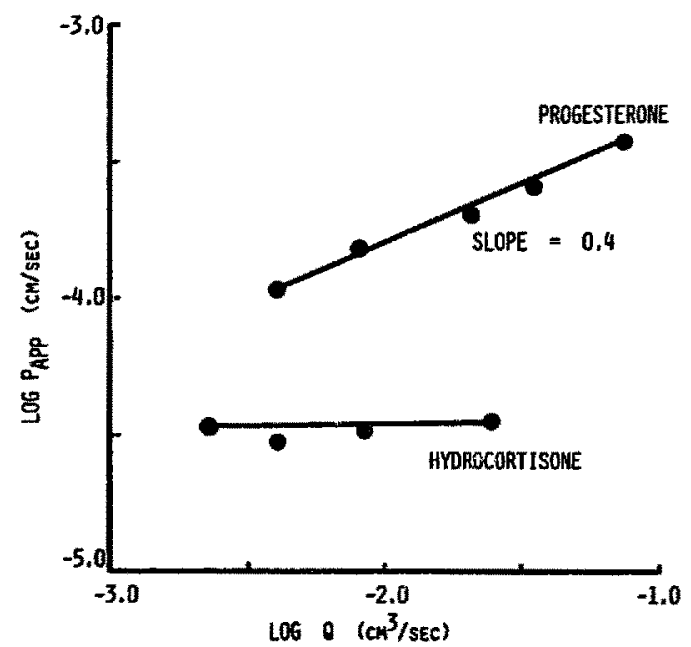

Fig. 7. Relationship of the apparent permeability coefficient of progesterone and hydrocortisone with flow-rate. The mass transport of progesterone is aqueous boundary layer-controlled in contrast to the membrane-controlled kinetics of hydrocortisone. 


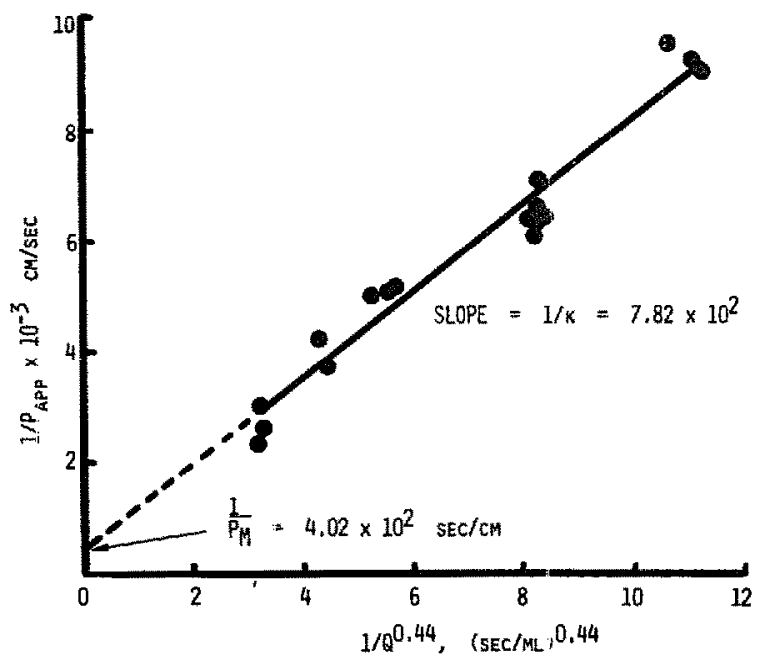

Fig. 8. Double reciprocal plot of the apparent permeability coefficient of progesterone and the (bulk fluid flow-rate) $)^{0.44}$.

hydrocortisone. As can be seen in Table 2, progesterone absorption in the ileum is identical to that in the jejunum and is governed by the permeability of the aqueous boundary layer. The ileal absorption of hydrocortisone is controlled by the permeability of the membrane. The permeability of hydrocortisone for the ileal membrane is smaller than that for the jejunum by a factor of two. These differences have been observed in the jejunal and ileal absorption of hydrocortisone in humans (Schedl, 1965) and were analyzed in the light of higher glucuronide conjugative activity in the jejunum than in the ileum (Ho et al., 1979), although there may be some differences in surface area.

The membrane permeability coefficients $\left(\mathrm{P}_{\mathrm{m}}\right)$ of hydrocortisone, dexamethasone and corticosterone are found in Table 4. These values are in good agreement with those determined by in situ rat intestinal absorption studies using the modified Doluisio technique (Ho et al., 1979).

\section{Hydrodynamic considerations}

The fact that this in situ rat intestinal absorption study has produced a quantitative insight into the relationship of the permeability coefficient and effective thickness of the aqueous boundary layer as a function of bulk fluid flow-rate, which the authors believe is the first of its kind for the small intestines, makes possible a critical discussion on the hydrodynamics in the small intestine.

The importance of the aqueous boundary layer as a hydrodynamic barrier that a drug molecule must traverse before arriving at the surface of a membrane has been demonstrated here and elsewhere. The existence of the hydrodynamic layer is also physically sound. The layer about a smooth surface has been theoretically described by the application of first principles (Levich, 1962); however, description of the layer on rough surfaces, such being the situation of the mucosal surface of the small intestines, is much 
TABLE 4

PERMEABILITY COEFFICIENTS OF VARIOUS STEROIDS IN THE RAT JEJUNUM AT $37^{\circ} \mathrm{C}$

\begin{tabular}{lllccc}
\hline Steroid & $\begin{array}{l}\text { Flow-rate } \\
(\mathrm{ml} / \mathrm{min})\end{array}$ & \multicolumn{4}{l}{ Permeability coefficients $\mathrm{a} \times 10^{5} \mathrm{~cm} / \mathrm{sec}$} \\
\cline { 3 - 7 } & & $\mathrm{P}_{\mathrm{app}}$ & $\mathrm{P}_{\mathrm{aq}}$ & $\mathrm{P}_{\mathrm{m}}$ & Average $\mathrm{P}_{\mathrm{m}}$ \\
\hline Hydrocortisone & 0.247 & 3.0 & 9.5 & 4.4 & 4.4 \\
& 0.494 & 3.3 & 13 & 4.4 & \\
Dexamethasone & 0.247 & 4.6 & 9.5 & 8.9 & 8.8 \\
& 0.494 & 5.2 & 13 & 8.7 & \\
Corticosterone & 0.247 & 5.5 & 9.5 & 13.1 & 13.9 \\
& 0.494 & 6.9 & 13 & 14.7 & \\
\hline
\end{tabular}

The $P_{a q}$ for each flow-rate was calculated from the plateau portion of Fig. 5 using Eqn. 4, whereupon $\mathrm{P}_{\mathrm{m}}$ was found using Eqn. 3.

more difficult and it demands knowledge of the height, shape and population density of the protrusions. As liquid flows along the tract of the small intestines, it encounters: (a) the hills and valleys of the numerous folds of Kerkring, most prominent in the duodenum and jejunum and less in the ileum; (b) the smaller hills and valleys of villous structures populating the folds; and (c) the little hills and valleys of the microvilli which populate the villi. Furthermore, the flow pattern will be influenced by: (d) the natural peristaltic activity of the intestinal tract; (e) the motility of the villi; (f) the multi-S-shaped course of the intestinal tract; and $(\mathrm{g})$ the presence of mucus on the membrane surface.

It is interesting in these present studies (see Table 3) that the estimated ratios of the aqueous boundary layer thickness to the radius of the distended intestinal lumen, i.e., $\delta / \mathrm{r}$, are about 0.4 at the slow flow-rate of $0.247 \mathrm{ml} / \mathrm{min}$ and about 0.1 at $4.2 \mathrm{ml} / \mathrm{min}$, which means that the boundary layer thicknesses are less than the radius of the lumen. This implies that the solution in the middle portion of the intestinal lumen in well mixed; that is to say, the concentration gradient to the membrane surface does not occur from the middle of the lumen. While the ratio of the average height of the villi to the lumen radius, $h / r$, which is 0.3 here, is an indicator of surface roughness, the ratio of effective boundary layer thickness to villous height, $\delta / \mathrm{h}$, is another kind of roughness indicator. As can be seen, the thickness of the layer is comparable to the height of the villi at slow flow-rates and becomes smaller than the villous height with increasing flow-rates. At the flow-rate of $2.14 \mathrm{ml} / \mathrm{min}$, which is comparable to the average flow-rate of $2 \mathrm{ml} / \mathrm{min}$ for a liquid meal in fasted humans (Soergel, 1971), the boundary layer thickness is approximately $60 \%$ of the height of the villi.

The hydrodynamic flow over the villous surface was of such nature that the permeability of the aqueous boundary layer is proportional to the 0.44 power of the flow velocity. Accordingly, the aqueous boundary layer thickness is inversely proportional to the same power relationship, i.e. $\delta \propto \mathrm{Q}^{-0.44}$. Mass transport across the hydrodynamic boundary layer occurs by a convective-diffusion mechanism. It is likely that the boundary layer tends to contour about the apical region of the densely populated villi. The effective thickness of the aqueous layer is thinner about the tips and thicker and less stirred in the 
valleys of the villi. Although the Kerkring folds increase the apparent surface area about 3-fold, the villi by 10 -fold and the microvilli by another factor of $20-24$ to bring about the total factor of approximately 600 (Glass, 1968), the effective surface area for absorption is shown to be less than the theoretical anatomical area of the membrane (Wilsor and Dietschy, 1974). This is due to a combination of reasons, i.e. the prevalent distribution of specialized absorption cells about the tips of villi and the difference in contour thicknesses of the aqueous boundary layer at the apical and valley regions of the villi.

In reviewing the theory of mass transport in a fluid boundary layer, one finds that the permeability of aqueous boundary layer, $P_{\mathrm{aq}}$, as a function of fluid velocity has the form (Levich, 1962):

$P_{\mathrm{aq}} \propto \mathrm{D}_{\mathrm{aq}}^{\mathrm{m}} \mathrm{U}_{0}^{\mathrm{n}}$

where $D_{a q}$ is the aqueous diffusion coefficient in $\mathrm{cm}^{2} / \mathrm{sec} ; \mathrm{U}_{\mathrm{o}}$ is the linear flow velocity in $\mathrm{cm} / \mathrm{sec}$, which, for a tube, is the ratio of the bulk fluid flow-rate and the cross-sectional area; and $m, n$ are exponents with values less than unity and greater than zero.

The power relationships of $D_{a q}$ and $U_{o}$ to $P_{a q}$, which have been derived for the dissolution of solids from various geometries into a sink, are found in Table 5. There are two striking features for smooth surfaces. Firstly, the power dependency on $U_{o}$ over the surfaces of a plate and tube or the angular velocity of a rotating disk is smaller in laminar conditions than in turbulent situations. Secondly, the power dependency on $D_{\mathrm{aq}}$ is not too different in laminar and turbulent conditions.

Similar theoretical relationships for rough surfaces are not as well developed. When rigid protuberances on a plate are higher than the boundary layer $(\mathrm{h} \gg>\delta)$ and the distances between them are sufficiently far apart, $\mathrm{P}_{\mathrm{aq}} \propto \mathrm{D}^{3 / 4} \mathrm{U}_{\mathrm{o}}^{0.45}$ in turbulent situations. However, when $\mathrm{h} \ll<\delta, \mathrm{P}_{\mathrm{aq}} \propto \mathrm{U}_{\mathrm{o}}^{0.9}$. In non-turbulent conditions, it is expected that $P_{a q} \propto D_{a q}{ }^{2 / 3} U_{0}^{1 / 2}$ even for rough surfaces. Theoretical development for small rough tubes

\section{TABLE 5}

POWER DEPENDENCE OF THE PERMEABILITY ${ }^{\circ}$ OF THE AQUEOUS BOUNDARY LAYER ON THE AQUEOUS DIFFUSION COEFFICIENT AND LINEAR FLOW VELOCITY FOR VARIOUS GEOMETRIC SURFACES UNDER LAMINAR AND TURBULENT CONDITIONS (LEVICH, 1962)

The term $h$ is the height of the protuberances of the rough surface and $\delta$ is the aqueous boundary layer thickness.

\begin{tabular}{lll}
\hline Geometry & Laminar conditions & Turbulent conditions \\
\hline Smooth surface rotating disk & $\mathrm{D}_{\mathrm{aq}}^{2 / 3} \omega^{1 / 2}$ & $\mathrm{D}_{\mathrm{aq}}^{3 / 4} \omega^{0.9}$ \\
Smooth surface straight tube & $\mathrm{D}_{\mathrm{aq}}^{2 / 3} \mathrm{U}_{0}^{1 / 3}$ & $\mathrm{D}_{\mathrm{ag}}^{3 / 4} \mathrm{U}_{0}^{0.875}$ \\
Smooth surface plate & $\mathrm{D}_{\mathrm{aq}}^{2 / 3} \mathrm{U}_{0}^{1 / 2}$ & $\mathrm{D}_{\mathrm{aq}}^{3 / 4} \mathrm{U}_{0}^{0.9}$ \\
Rough surface plate & $\mathrm{D}_{\mathrm{aq}}^{2 / 3} \mathrm{U}_{0}^{1 / 2}(\delta>>\mathrm{h})$ & $\mathrm{D}_{\mathrm{ag}}^{3 / 4} \mathrm{U}_{0}^{0.9}(\delta>>\mathrm{h})$ \\
& & $\mathrm{D}_{\mathrm{aq}}^{3 / 4} \mathrm{U}^{0.45}(\delta<\mathrm{h})$ \\
Rough surface straight tube & Undeveloped & Undeveloped \\
\hline
\end{tabular}

a For flowing liquids over stationary surfaces, $P_{\mathrm{gq}} \propto U_{0}^{n}$ where $U_{0}$ is the linear flow velocity. Otherwise, $P_{\mathrm{aq}} \propto \omega^{n}$ where $\omega$ is the angular rotational velocity of the disk. 
similar to the dimensions within the intestinal tract (i.e. number of projections per $\mathrm{cm}^{2}$ and ratio of protuburence height to tube diameter) is difficult to find.

It is interesting that $P_{a q}$ is related to the flow-rate by approximately 0.44 power dependence in this study. The expected power dependencies are 0.333 and 0.9 for laminar and turbulent flow, respectively, in a smooth straight tube.

It is noteworthy that the estimations in the aqueous boundary layer thicknesses are in reasonable agreement with the data of others. Using a perfusion rate of $0.5 \mathrm{ml} / \mathrm{min}$, Winne (1976 and 1979) recently estimated a lower limit value of about $500 \mu \mathrm{m}$ for the rat jejunum based upon the appearance rate of $L$-phenylalanine in blood. This is in very good agreement with our result based upon uptake data. Read and associates (1977) at Sheffield recently used an electrical method to estimate a value of $632 \mu \mathrm{m}$ for the unstirred layer in healthy man. Their flow-rate was $5 \mathrm{ml} / \mathrm{min}$ which would correspond to an average lumen linear flow velocity, $\beta$, of around $1.6 \mathrm{~cm} / \mathrm{min}$ and somewhat below the lowest $\beta$ in our experiments. If the data in Table 3 are extrapoiated to a linear velocity of $1.6 \mathrm{~cm} / \mathrm{min}$, the $\delta$ value would be around $840 \mu \mathrm{m}$ for the present rat perfusion system. A further extrapolation to the human situation is of interest. Based upon our 0.44 power dependence, an extrapolated value for $\delta$ in Soergel's study (1971) of the flow-rate for a liquid meal in fasted humans would be around $950 \mu \mathrm{m}$ for the flow rate of $2 \mathrm{ml} / \mathrm{min}(\beta$ value of around $0.6 \mathrm{~cm} / \mathrm{min}$ ).

\section{REFERENCES}

Amidon, G.E., Rotating Membrane Diffusion Studies of Micellar and Suspension Systems, P'.D. Thesis, The University of Michigan, Ann Arbor, Mich., 1979.

Boley, S.J., Vascular Disorders of the Intestine, Meredith, New York, N.Y., 1971, pp. 431.

Ho, N.F.H. and Higuchi, W.I., Theoretical model studies of intestinal drug absorption IV. J. Pharm. Sci. 63 (1974) 686-690.

Ho, N.F.H., Park, J.Y., Amidun, G.E., Ni, P.F. and Higuchi, W.I., Methods for interrelating in vitro, animal and human studies. In Aguiar, A.J. (Ed.) Gastrointestinal Absorption of Drugs, American Pharmaceutical Association, Academy of Pharmaceutical Sciences, Washington, D.C., 1979.

Glass, G.B.J., Introduction to Gastrointestinal Physiology, Prentice-Hall, Englewood Cliffs, N.J., 1968, pp. 146.

Levich, V.G., Physicochemical Hydrodynamics, Ch. 2 and 3, Prentice-Hall, Englewood Cliffs, N.J., 1962.

Lewis, L.D. and Fordtran, J.S., Effect of pat fusion rate on absorption, surface area, unstirred layer thickness, permesbility and intraluminal pressure in the rat ileum in vivo. Gastroenterology, 68 (1975) $1509-1516$.

Poarse, A.G.E. and Riecken, E.O., Histology and cytochemistry of the cells of the small intestine in relation to absorption. Br. Med. Bull., 23 (1967) 217-222.

Schedl, H.P., Absorption of steroid hormones from the human small intestines. J. Clin. Endocrin., 25 (1965) 1309-1316.

Schlichting, H., Boundary Layer Theory, Ch. 2. Mc(jraw-Hill, New York, N.Y., 1955.

Soorgel, K.H., Flow measurements of test meals and fasting contents in human small intestine. In Demling, $L$. (Ed) Proceedings of the International Symposium on Motility of the Gastrointestinal Tract, Georg Thieme Verlag, Stuttgart, 1971, pp. 81-916.

Vorzar, F. and McDougall, E.J., Absorption from the Intestine, Hafner, New York, N.Y., 1967. Ch. 3.

Wilson, I.A. and Dietschy, J.M., The intestinal unstirred layer: its surface area and effect on active transport kinetics. Biochim. Biophys. Acta, 363 (1974) 112-126.

Road, N.W., Burber, D.C., Levin, R.J. and Holdsworth, C.D., Unstirred layer and kinetics of electrogenic glucose absorption in the human jejunum in situ. Gut, 18 (1977) 865-876.

Winne, D., Unstirred layer thickness in perfused rit jejurum in vivo. Experientia, 32 (1976) 12781279.

Winne, D., Rat jejunum perfused in situ: effect of perfusion rate and intraluminal perfusion rate and intraluminal radius on absorption rate and effective unstirred layer thickness. Naunyn-Schmiedeberg's Arch. Pharmacol., 307 (1979) 265-274. 